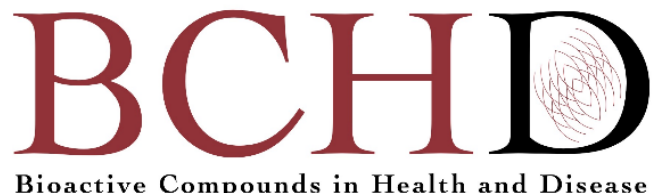

\title{
The effect of cold plasma on antioxidant enzymes, minerals, and some of the levels of the biochemical parameters in the subjects with type 2 diabetes mellitus samples
}

\section{Danik Martirosyan', Hamid Ghomi², Mohammad Reza Ashoori ${ }^{3}$, Alireza Rezaeinezhad², Hossein Mirmiranpour ${ }^{4 *}$}

${ }^{1}$ Functional Food Center, Functional Food Institute, Dallas, TX, USA; ${ }^{2}$ Laser and Plasma Research Institute, Shahid Beheshti University, G. C., Tehran, Iran; ${ }^{3}$ Department of Laboratory Sciences, School of Health and Allied Medical Sciences, Zanjan University of Medical Sciences, Zanjan, Iran; ${ }^{4}$ Endocrinology and Metabolism Research Center (EMRC), Vali-Asr Hospital, School of Medicine, Tehran University of Medical Sciences, Tehran, Iran

"Corresponding Author: Hossein Mirmiranpour, MD, PhD, Endocrinology and Metabolism Research Center (EMRC), Vali-Asr Hospital, School of Medicine, Tehran University of Medical Science, Keshavarz Boulevard, Tehran, Iran.

Submission Date: January 27 $7^{\text {th }}$ 2021; Acceptance Date: February 18 ${ }^{\text {th }}, 2021$; Publication Date: February $26^{\text {th }}, 2021$

Please cite this article as: Martirosyan D., Ghomi H., Ashoori M.R., Rezaeinezhad A., Mirmiranpour H. The effect of cold plasma on antioxidant enzymes, minerals, and some of the levels of the biochemical parameters in the subjects with type 2 diabetes mellitus samples. Bioactive Compounds in Health and Disease 2021. 4(2): 14-23. DOI: https://www.doi.org/10.31989/bchd.v4i2.783

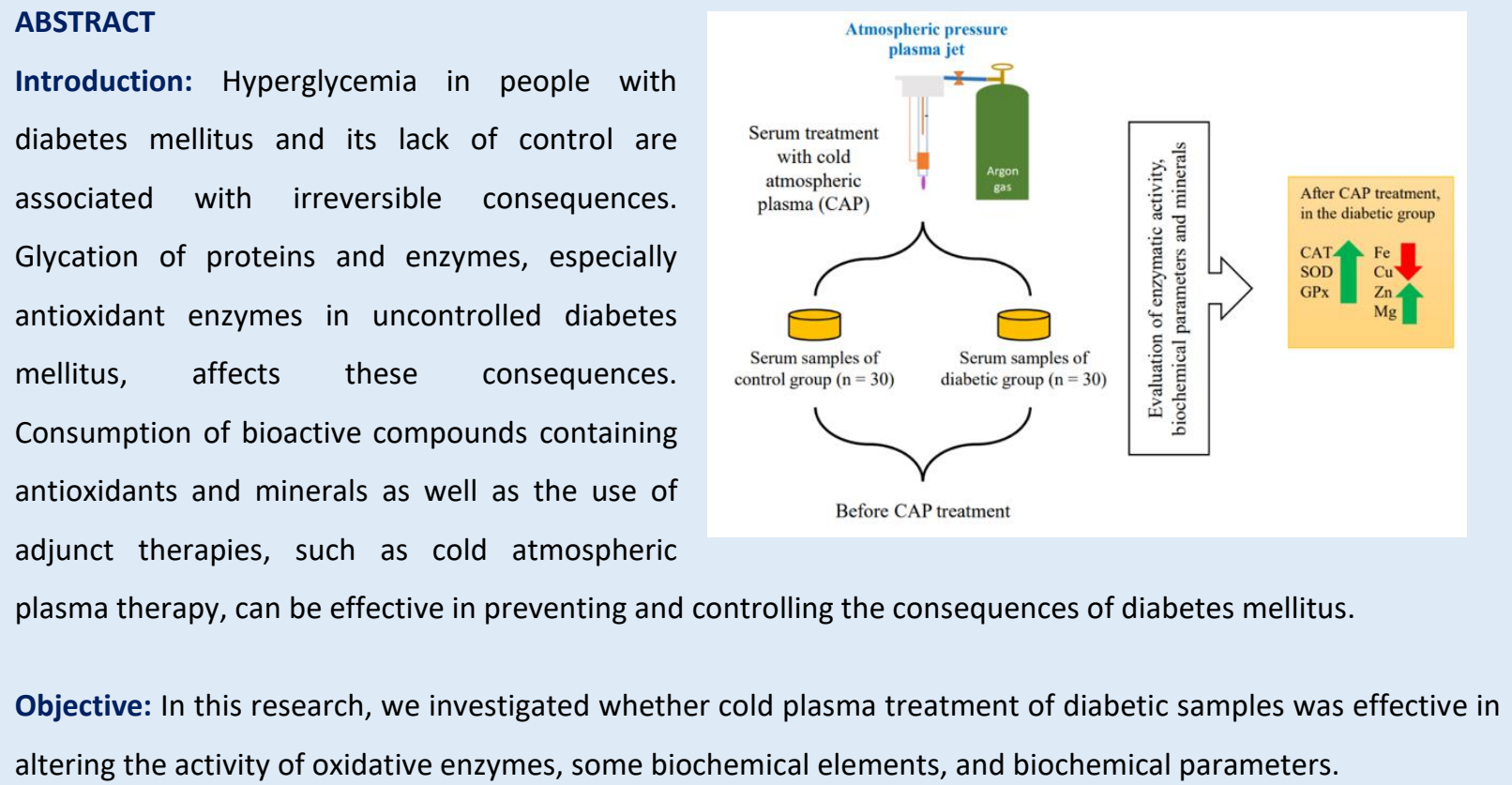


Methods: Thirty individuals with type 2 diabetes mellitus and 30 healthy individuals, as controls, participated in the study. The samples were exposed to cold argon plasma jet for 10 minutes (by a $10 \mathrm{kHz}$ pulsed DC power supply with an amplitude up to $20.0 \mathrm{kV}$ ). The following contents of the serum samples of all participants were evaluated according to the instructions of the used kits before and after the cold argon plasma jet treatment: the activity of catalase, superoxide dismutase, and glutathione peroxidase enzymes; the concentration of glucose, hydrogen peroxide, and selenium binding protein 1 (as an indicator of blood selenium); and the concentration of copper, zinc, iron, and magnesium.

Results: The activity of antioxidant enzymes and minerals significantly increased in diabetic samples treated with cold plasma ( $P$ value $<0.05$ ). No significant changes were observed in the concentrations of glucose, hydrogen peroxide, or selenium binding protein 1 in diabetic samples treated with cold plasma.

Conclusions: Using cold argon plasma jet as an adjunct method, which will reduce the glycation of enzymes and improve some minerals, can reduce the risk of diabetes complications in patients with diabetes mellitus.

Keywords: Antioxidant enzymes, Cold plasma, Diabetes mellitus, Minerals.

CFFC 2021. This is an Open Access article distributed under the terms of the Creative Commons Attribution 4.0 License (http://creativecommons.org/licenses/by/4.0)

\section{INTRODUCTION}

Type 2 diabetes mellitus (T2DM), as a type of diabetes, is a chronic metabolic disease which many individuals today suffer from [1,2]. Genetics, obesity, and lifestyle are the most important risk factors for T2DM [3]. In the case of genetics, nothing can be done, but by improving and optimizing one's lifestyle, this disease can be prevented [4]. Failure to control T2DM, however, may result in irreparable consequences. Taking medications, such as metformin, exercising, and eating foods rich in antioxidants and trace elements, which are available in bioactive compounds, can be important in controlling type 2 diabetes $[5,6]$. The consequences of uncontrolled T2DM are the result of reactive oxygen species [7] and oxidative stress. In uncontrolled T2DM, hyperglycemia can increase advanced glycation end products (AGEs) [8] and reactive oxygen species (ROS). ROS and AGEs play a role in causing the consequences of T2DM (such as neuropathy, retinopathy, nephropathy, and diabetic ulcers) by altering cellular signaling, increasing the production of oxidative stress and apoptosis, and increasing the expression of pro-inflammatory cytokines [9].

Consumption of antioxidants in bioactive compounds can be effective in preventing and controlling T2DM as well as reducing its complications [10]. For example, some vitamins can directly or indirectly counteract the effects of free radicals in diabetes mellitus (DM) [11]. Studies have shown that increasing the expression of antioxidant enzymes such as superoxide dismutase (SOD), glutathione peroxidase (GPx), or catalase (CAT) and altering trace element levels may play a role in reducing free 
radicals and subsequently reducing the effects of DM. In summation, some of the minerals, trace elements, and antioxidants in bioactive compounds have antidiabetic effects [12-15].

Previous studies have examined the effectiveness of adjunct therapies, such as laser and plasma therapy in improving and reducing the consequences of DM [8, 16, 17]. In our previous study, the effect of photobiomodulation on some biochemical parameters, antioxidant enzymes, and minerals in blood samples of people with T2DM was investigated [7]. One of the most modern methods to kill bacteria and fungi, especially in the food processing industry, is the use of cold plasma. A fully ionized gas containing substances such as photons and free electrons with excited atoms with a neutral charge is called a plasma. Plasma was first used for germs inactivation in the year 1960 [18]; in recent years, different types of plasma have been used for medical applications such as healing skin wounds [17, 19-21]. It has been shown that plasma is effective in improving the activity of antioxidant enzymes such as CAT and SOD [22]. In our previous study, glycated GPx, due to hyperglycemia, was exposed to cold plasma, and an increase in the activity of this enzyme was observed [23]. In this research, the effect of cold plasma, as an adjunct method, on the levels of glucose, hydrogen peroxide $\left(\mathrm{H}_{2} \mathrm{O}_{2}\right)$, antioxidant enzymes, and some minerals was studied.

\section{METHODS}

An enzyme assay kit to investigate the concentration of SOD was purchased from Biovision Co. (BioVision Incorporated, USA). Measurement kits to evaluate the concentration of antioxidant enzymes GPx and CAT were purchased from Biocore Co. The enzymelinked immunosorbent assay (ELISA) kit to assay glucose levels was purchased from MyBioSource Inc. (San Diego, USA). An assay kit was purchased for the measurement of $\mathrm{H}_{2} \mathrm{O}_{2}$ levels from ZellBio (ZellBio $\mathrm{GmbH}, \mathrm{UIm}, \mathrm{Germany})$. In this study, the number of minerals such as zinc ( $\mathrm{Zn})$, iron (Fe), copper (Cu), and magnesium (Mg) as well as selenium binding protein 1 (Sebp1) concentration, which indicates the concentration of selenium, were measured by kits purchased from MyBioSource Inc. (San Diego, USA). All biochemical parameters including glucose, $\mathrm{H}_{2} \mathrm{O}_{2}$, antioxidant enzymes, and minerals were measured according to the instructions of the respective kits. $A$ microplate spectrophotometer (Fluostar, Bmglabtech, Germany) and a microplate reader (Mindray, MR-96A, Germany) were used for this assay.

Cold atmospheric plasma (CAP): In this study, an atmospheric pressure plasma jet (APPJ) device was used. The plasma was generated by a $10 \mathrm{kHz}$ pulsed DC power supply with an amplitude up to $20.0 \mathrm{kV}$. Also, argon gas with a purity of $99.9 \%$ and $31 \mathrm{~min}^{-1}$ flow rate was used as feeding gas. The APPJ used in this study consisted of dielectric, powered, and ground electrodes and a high voltage power supply. A Pyrex tube (L: $150 \mathrm{~mm}$, ID: $4 \mathrm{~mm}$, OD: $6 \mathrm{~mm}$ ) was utilized as the dielectric barrier and the nozzle. A copper rod (L: $30 \mathrm{~mm}$, D: $1 \mathrm{~mm}$ ) and a thin copper cylindrical tube ( $\mathrm{L}: 15 \mathrm{~mm}$ ) were used as the powered and ground electrodes, respectively. The powered electrode was inserted in the tube from one end, while the other tube end was surrounded by the ground electrode, such that the distance between the nozzle tip and the lower edge of the ground electrode was $5 \mathrm{~mm}$. The experimental setup has been shown in Figure 1. 


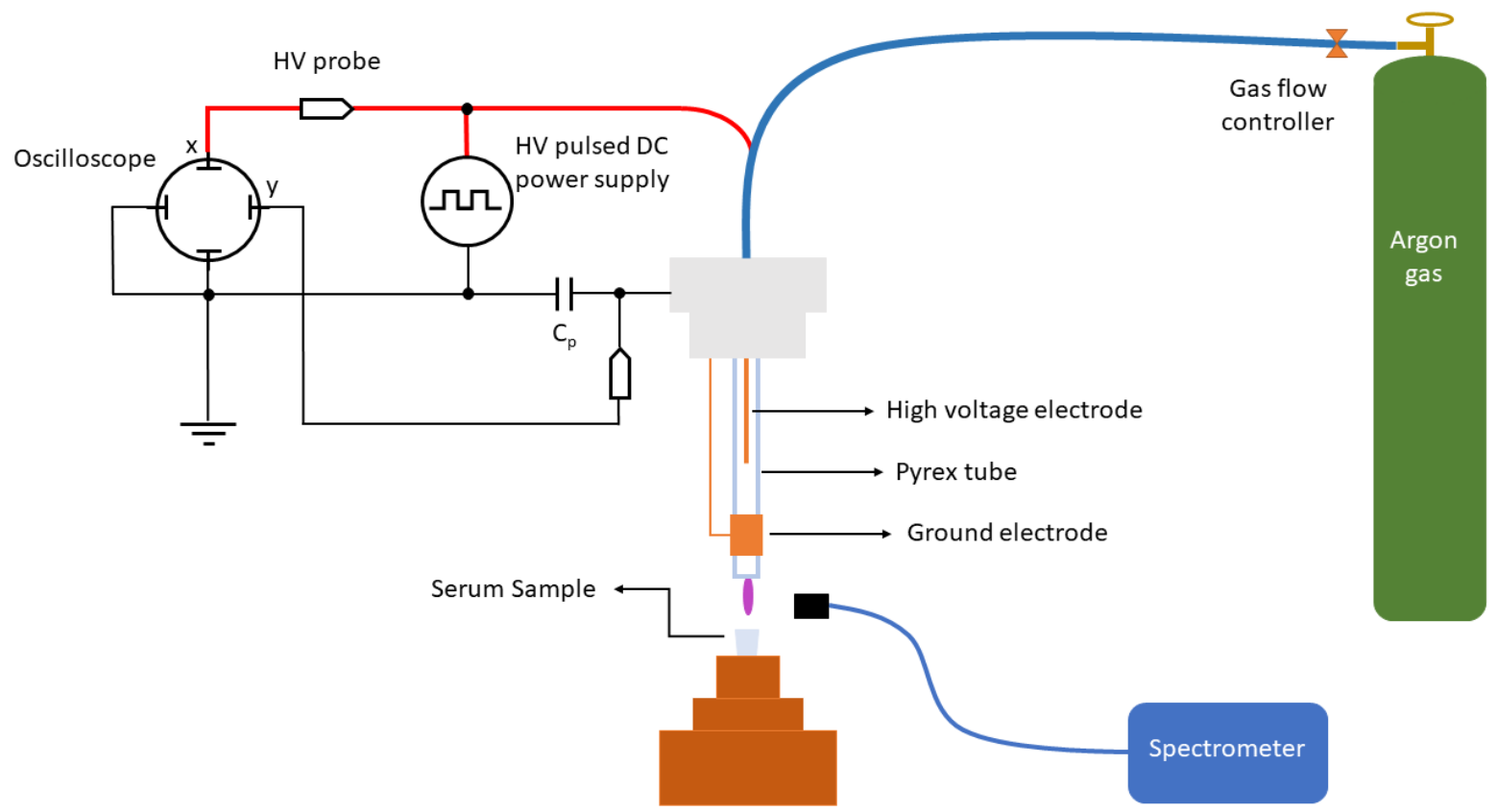

Figure 1. The experimental setup

Power measurement. The average power feeding the reactor is measured by the Lissajous curve approach which is shown in Figure 2. Therefore, a capacitor is connected in series with the reactor, as presented in Figure 1. Based on the capacitor voltage and Ohm's law, the power can be calculated as follows:

$$
\begin{gathered}
q_{p}=C_{p} V_{p} \\
C_{r}=\frac{q}{V_{r}} \\
P=f \cdot E=f \cdot \oint_{T} \frac{V(t) d q}{d t} d t=f \cdot C_{r} \oint V(t) d V
\end{gathered}
$$

Where $q$ is the stored charge in the capacitor and $C_{p}$ is the capacitance of the capacitor. $C_{r}$ is the capacitance of the reactor, $V(t)$ is the applied voltage, and $f$ is the frequency of the applied voltage. According to the Lissajous curve, the average power consumed by plasma is $12.68 \mathrm{~W}$.

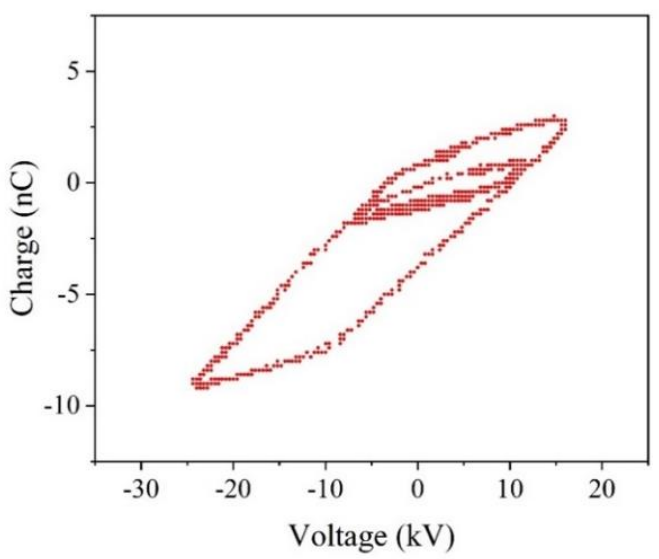

Figure 2. The Lissajous curve about our experimental electric field applied to the sample 
Optical emission spectroscopy (OES): CAP applicability is generally based on the production capacity of adequate reactive species amounts. Therefore, OES (Ocean Optics HR 2000 spectrometer) is applied to investigate the presence and intensity of each species. The range of 200 to $11000 \mathrm{~nm}$, with a resolution of $0.5 \mathrm{~nm}$, is chosen as the spectral range. The optical emissions of CAP are recorded at a $10 \mathrm{~mm}$ distance on the axis of the cold plasma stream. The recorded spectrum is analyzed based on the atomic spectra database lines, and different species are identified. The emission spectrum of argon plasma jets in the air medium is shown in our previous study [23]. The spectrum line of argon plasma jet indicates the existence of hydroxyl radicals and nitrogen, argon, and oxygen active species.

Participants: In this study, 100 volunteers were randomly selected from those who were referred to the Valiasr Medical Laboratory in Tehran, Iran. Among them, 30 people with T2DM and 30 healthy people, as the control group, were randomly selected. The selected healthy individuals did not have any disease; individuals with any disease were excluded. In reviewing the history of people with T2DM, these people did not have other diseases or abnormalities. People with type 1 diabetes mellitus (T1DM) and other diseases were excluded from the study. The diagnostic criteria T2DM in selected individuals were based on World Health Organization (WHO) criteria: fasting plasma glucose $\geq 126 \mathrm{mg} / \mathrm{dL}$ or glycated hemoglobin $(\mathrm{HbA} 1 \mathrm{c}) \geq 6.5 \%$. A protocol of the study was accepted by the Ethics Board of Shahid Beheshti University, on June 20, 2020, with ID Approval: IR.SBU.REC.1399.050. Written consent was obtained from all selected individuals for the study. During the study, people with T2DM were asked to take their main medications.
Sampling and anthropometric parameters: Blood samples were taken from all participants after 12 hours of fasting. Then, serum was obtained from the collected samples by centrifugation at $250 \mathrm{~g}$ for 10 minutes. Serum samples obtained from healthy individuals and individuals with T2DM were divided into two groups. Group 1: before cold plasma treatment and group 2: after cold plasma treatment. Before starting the study, sex, age, weight, and body mass index (BMI), as anthropometric parameters, of all participants were recorded.

Cold plasma treatment: Serum samples from controls and people with T2DM were exposed to cold plasma for 10 minutes. The specifications of the device (APPJ) used to produce cold plasma are described above.

Statistical analysis: SPSS (version 23, IBM, USA) software for Windows was used for statistical analysis of the obtained data. The Kolmogorov-Smirnov test was used to analyze the normal distribution of data obtained from this study, and an independent-sample T-test was used to compare the data obtained from the general characteristics of all participants. Oneway ANOVA was used to compare the mean of the data obtained from the studied groups. After a oneway ANOVA test, Tukey post hoc was used. All results were expressed as mean \pm standard deviation. $P$ values $<0.05$ were considered significant.

\section{RESULTS}

Anthropometric parameters: In this observational study, as previously stated, 30 individuals with T2DM and 30 healthy individuals, as controls, were randomly selected. The ratio of males to females in these two groups was equal (15 males and 15 
females), and all participants were between 50 and 65 years old. General parameters such as weight, height, and BMI between the control group and group with T2DM are shown in Table 1 . In the group with T2DM, these parameters were not significant in comparison with the healthy control group.

Table 1. Anthropometric parameters

\begin{tabular}{|c|c|c|c|}
\hline $\begin{array}{l}\text { Group } \\
\text { Parameters }\end{array}$ & $\begin{array}{l}\text { Control } \\
n=30\end{array}$ & $\begin{array}{l}\text { Diabetic } \\
n=30\end{array}$ & $P$ value \\
\hline Weight (Kg) & $82.7 \pm 2.5$ & $83.5 \pm 3.6$ & 0.61 \\
\hline Height (Cm) & $163.7 \pm 3.6$ & $162.8 \pm 2.6$ & 0.46 \\
\hline $\mathrm{BMI}^{1}\left(\mathrm{Kg} / \mathrm{m}^{2}\right)$ & $30.8 \pm 1.1$ & $31.7 \pm 2.0$ & 0.37 \\
\hline
\end{tabular}

Data are given as mean \pm SD. $P$ value $<0.05$ is significant.

1. Body mass index

\section{Biochemical parameters and minerals assay: The} activity of antioxidant enzymes, including CAT, SOD, and GPx was measured before and after treatment of all samples by cold plasma was taken from individuals with T2DM and the control group. The results obtained from the assay of these enzymes are shown in Figure 3. As shown in Figure 3, the activity of these antioxidant enzymes in patients with T2DM have decreased compared to controls, and this decrease was significant $(P$ value $<0.001)$. There was no significant difference in the levels of GPX and CAT in the samples of control subjects before and after cold plasma treatment $(P$ value $=0.27$ and 0.16 respectively). However, in control subjects, significant differences in SOD levels were observed in cold plasma-treated samples compared to untreated samples ( $P$ value < 0.001). Comparatively, GPx, SOD, and CAT activities in cold plasma-treated diabetic samples showed a significant increase compared to untreated diabetic samples $(P$ value $=0.006)$. There was also a significant difference in the levels of antioxidant enzymes in patients with T2DM before and after cold plasma treatment $(P$ value $=0.06$ for GPx and < 0.001 for CAT and SOD).

Comparison of serum glucose and $\mathrm{H}_{2} \mathrm{O}_{2}$ levels in patients with T2DM compared to controls showed a significant difference $(P$ value $<0.001)$. In a comparison of glucose and $\mathrm{H}_{2} \mathrm{O}_{2}$ levels, no significant difference was observed between samples treated with cold plasma and untreated samples in control ( $P$ value $=0.98$ and 0.89 respectively) and diabetic groups $(\mathrm{P}$ value $=0.14$ and 0.91 respectively). These results are given in Table 1. Sebp1 (as an indicator of the amount of selenium in the serum), $\mathrm{Mg}, \mathrm{Fe}, \mathrm{Cu}$, and $\mathrm{Zn}$ were measured in samples of control and diabetic groups before and after cold plasma treatment. The Sebp1 level and mentioned minerals levels in the diabetic group showed a significant difference compared to the levels in the control group. In the diabetic group, the levels of Sebp1, Mg, and $\mathrm{Zn}$ decreased in comparison to the control group ( $P$ value $<0.001$ ), while the levels of $\mathrm{Fe}$ and $\mathrm{Cu}$ increased in comparison ( $P$ value < 0.001). Comparison of Sebp1 and minerals levels in the control group samples before and after cold plasma treatment did not show a significant difference $(P$ value $>0.05)$. In the treatment of samples from the diabetic group by cold plasma, except for Sebp1 (P value $=0.86)$, the levels of minerals showed $\mathrm{a}$ significant difference compared to the untreated samples ( $\mathrm{P}$ value $<0.001$ for $\mathrm{Fe}, \mathrm{Mg}$, and $\mathrm{Zn}$ and $\mathrm{P}$ value $=0.003$ for $\mathrm{Cu}$ ). The results of the study of Sebp1 and Mg are shown in Table 1 and the results of the study of $\mathrm{Fe}, \mathrm{Cu}$, and $\mathrm{Zn}$ are shown in Figure 4. 


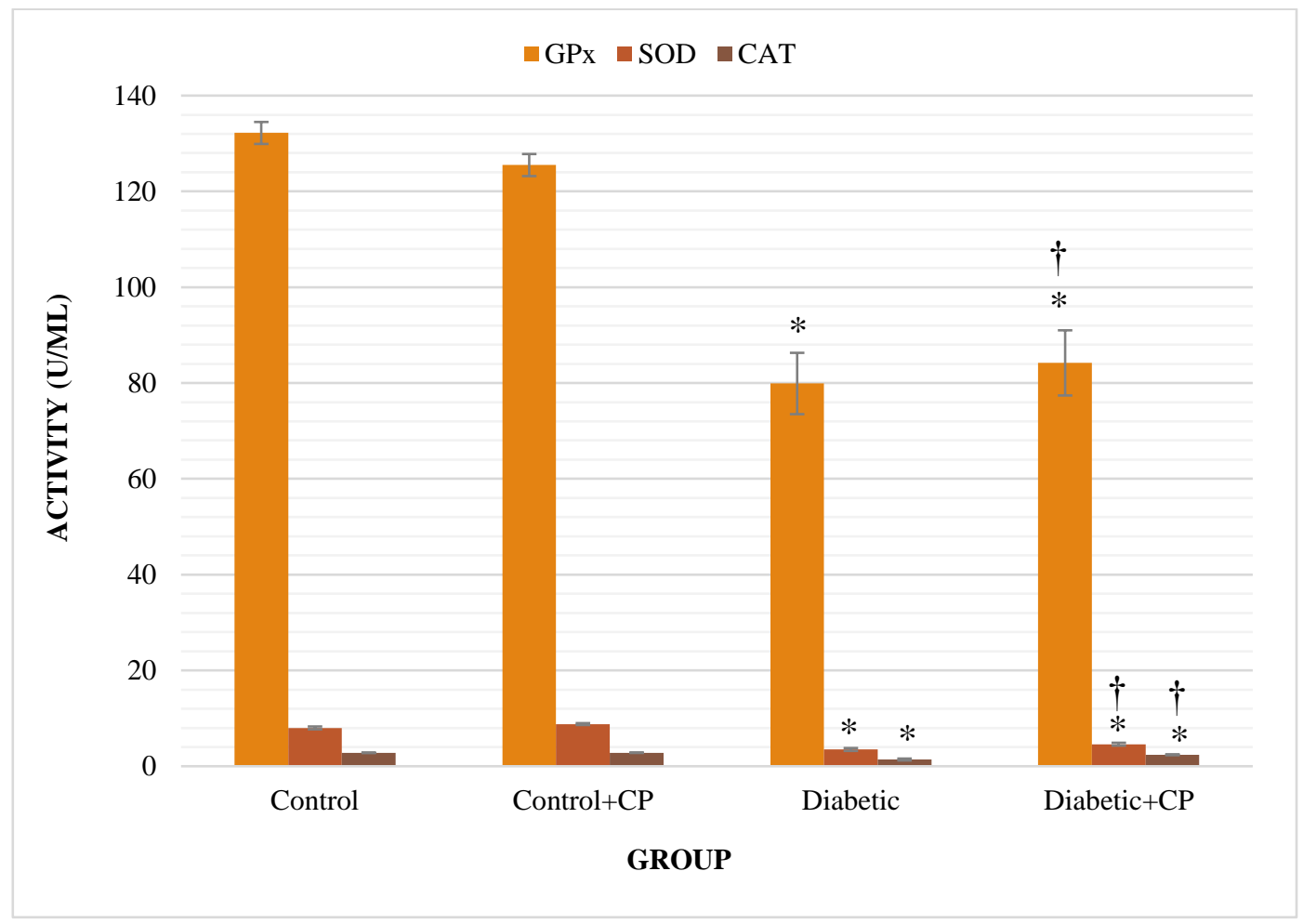

Figure 3. Changes in the serum enzyme activities in the control and diabetic samples before and after treatment by cold plasma - CP means cold plasma.

*Significances of data comparing diabetic samples vs. the control samples. † Significances of data comparing treated diabetic samples by cold plasma vs. the untreated diabetic samples $(p<0.05)$.

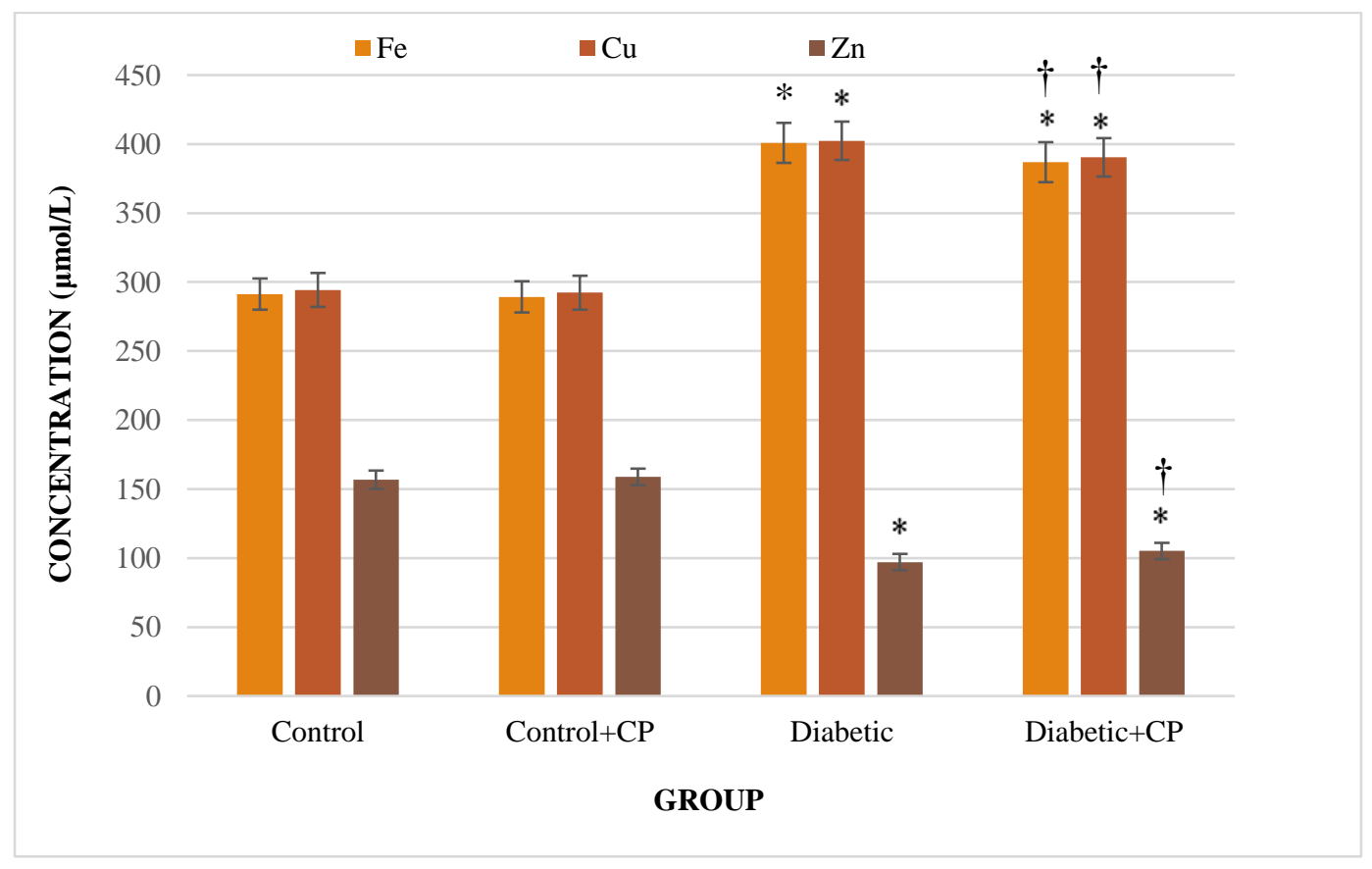

Figure 4. Changes in serum iron, copper, and zinc concentrations in the control and diabetic samples before and after treatment by cold plasma - CP means cold plasma.

* Significances of data comparing diabetic samples vs. the control samples. † Significances of data comparing treated diabetic samples by cold plasma vs. the untreated diabetic samples $(p<0.05)$. 
Table 2. Comparison between the concentrations of biochemical parameters, before and after cold plasma treatment in the various groups

\begin{tabular}{|c|c|c|c|c|c|c|}
\hline $\begin{array}{l}\text { Group } \\
\text { Parameter }\end{array}$ & $\begin{array}{l}\text { Control } \\
n=30\end{array}$ & $\begin{array}{l}\text { Control + CP1 } \\
n=30\end{array}$ & $P$ value & $\begin{array}{l}\text { Diabetic } \\
n=30\end{array}$ & $\begin{array}{l}\text { Diabetic + CP } \\
n=30\end{array}$ & P value \\
\hline $\mathrm{GIC}^{2}(\mu \mathrm{mol} / \mathrm{ml})$ & $211.6 \pm 19.5$ & $209.6 \pm 19.5$ & 0.98 & $460 \pm 20$ & $456 \pm 20$ & 0.91 \\
\hline $\mathrm{H}_{2} \mathrm{O}_{2}(\mu \mathrm{g} / \mathrm{ml})$ & $193.6 \pm 19.6$ & $189.6 \pm 19.6$ & 0.89 & $359.2 \pm 23.5$ & $347.2 \pm 23.5$ & 0.14 \\
\hline Sebp $1^{3}(\mathrm{pg} / \mathrm{ml})$ & $4973.1 \pm 289.6$ & $4979.1 \pm 289.6$ & 1 & $3163.1 \pm 289.6$ & $3221.1 \pm 289.6$ & 0.86 \\
\hline $\mathrm{Mg}^{4}(\mathrm{mmol} / \mathrm{L})$ & $7.1 \pm 0.8$ & $7.2 \pm 0.8$ & 0.96 & $3.9 \pm 0.8$ & $5.0 \pm 0.8$ & $<0.001$ \\
\hline
\end{tabular}

Data are given as mean \pm SD. P value $<0.05$ is significant.

1. Cold plasma, 2. Glucose, 3. Selenium binding protein 1, 4. Magnesium.

\section{DISCUSSION}

In the present study, the effect of cold plasma on serum samples of people with T2DM was investigated. The aim of treating serum samples was to study changes in the activity of antioxidant enzymes (CAT, SOD, and GPx) and biochemical factors (such as glucose, $\mathrm{H}_{2} \mathrm{O}_{2}$, and some minerals) in individuals with T2DM and compare the samples to those of healthy individuals. The production of oxidants and ROSs in DM and their role in the consequences of DM are important and should be researched. Studies have shown that some types of plasma are involved in the development of ROS [24]. ROS are dangerous to cells in the long term and affect the cell's functionality. It has been stated that ROS act as a two-edged sword in biology - this means that they can be both beneficial and harmful [25]. Plasmaderived ROS is responsible for lipid peroxidation in bacterial membranes, DNA damage in cancer cells, and growth factor release in proliferating cells [26]. Hyperglycemia in patients with uncontrolled DM is involved in the glycation of proteins and enzymes.

The role of SOD in the body is to eliminate the superoxide anion $\left(\mathrm{O}_{2}{ }^{-}\right)$by converting it to $\mathrm{H}_{2} \mathrm{O}_{2}$. Following the production of $\mathrm{H}_{2} \mathrm{O}_{2}, \mathrm{GPx}$ and CAT enzymes catalyze and convert it to water and oxygen [27]. According to the results of our study, shown in
Figure 3 , the activity of antioxidant enzymes in cold plasma-treated diabetic samples increased compared to untreated diabetic samples. These results were in agreement with the results of our previous work; however, in the previous study, only the activity of GPx was examined [23]. In that study, an increase in the activity of GPx was reported in the blood samples of diabetic mice exposed to cold plasma. In a study by Cheng et al., the activity of CAT, SOD, and GPx enzymes was examined in the tissues of diabetic rats. Their study reported an increase in the activity of these enzymes after plasma treatment [21]. In this respect, our study agrees with that of Cheng et al.

It has been reported that some minerals, such as

zinc, have antioxidant and anti-inflammatory properties [28]. This may be because minerals are at the active site of some antioxidant enzymes. As shown in Figure 4, the concentrations of Fe and $\mathrm{Cu}$ in diabetic samples increased significantly. Despite the increase in $\mathrm{Fe}$ and $\mathrm{Cu}$ concentrations, $\mathrm{Zn}$ concentrations decreased in diabetic samples. By treating diabetic samples with cold plasma, however, $\mathrm{Fe}$ and $\mathrm{Cu}$ concentrations decreased while $\mathrm{Zn}$ concentrations increased (Figure 4). As shown in Table 2, by treating the samples with cold plasma, a significant increase in $\mathrm{Mg}$ concentration was observed, but no significant increase in Sebp1 was observed. 
The study of mineral concentrations in treated samples by cold plasma was performed for the first time in this study as similar studies of the effect of cold plasma on minerals in human serum samples have yet to be performed. Bioactive compounds contain minerals and antioxidants that can be used to control and even prevent DM. Table 2 shows the results of glucose and $\mathrm{H}_{2} \mathrm{O}_{2}$ concentrations in participants with T2DM and healthy individuals before and after cold plasma treatment. In our previous study, a decrease in glucose and $\mathrm{H}_{2} \mathrm{O}_{2}$ concentrations was observed in samples of diabetic mice treated with cold plasma. In terms of changes in glucose and $\mathrm{H}_{2} \mathrm{O}_{2}$ concentrations, the results obtained in this study were in agreement with the results of our previous study [23]. However, in the present study, no significant reduction was observed in these two parameters.

\section{CONCLUSION}

An increase in blood glucose leads to DM, and DM causes an increase in ROS and oxidants. These compounds, along with inflammatory factors, play a role in the consequences of DM. Antioxidants and minerals that play a role in the function of antioxidant enzymes (as cofactors) can play an important role in the prevention and control of DM. These antioxidants and minerals are present in bioactive compounds and therefore their consumption is highly recommended. The use of cold plasma along with the consumption of bioactive compounds can be useful in controlling and improving the consequences of DM such as diabetic ulcers. The results of this study revealed that cold plasma as an adjunct method can be effective in reducing the effects of hyperglycemia on proteins and enzymes in people with DM and can also improve the activity of antioxidant enzymes as well as some minerals. Certainly, more research is needed in this area.

List of abbreviations: DM: diabetes mellitus, T1DM: type 1 diabetes mellitus, T2DM: type 2 diabetes mellitus, WHO: World Health Organization, CAP: cold atmospheric plasma, APPJ: atmospheric pressure plasma jet, GPx: glutathione peroxidase, CAT: catalase, SOD: superoxide dismutase, ROS: reactive oxygen species, AGE: advanced glycation end product, BMI: body mass index, Sebp1: selenium binding protein 1, Fe: Iron, Mg: Magnesium, Zn: Zinc, Cu: Copper.

Acknowledgments: The authors of this article sincerely acknowledge the staff at Laser and Plasma Research Institute, Shahid Beheshti University.

Competing interests: The authors declare that there are no conflicts of interest.

Author's contributions: The authors confirm contributions to the paper are as follows: DM participated in the study design and the article edition. HG performed experiments and treatment of samples with cold plasma by atmospheric pressure plasma jet device; MRA participated in the writing and analysis of the results; AR assisted in experiments; HM contributed to the original idea of the paper, doing the experimental work and data collection. All authors read and approved the final version before its submission.

Human and animal studies: This article contains human studies - all of which were consented and humane. No animal studies were conducted. 


\section{REFERENCES}

1. Punthakee Z, Goldenberg R, Katz P: Definition, classification and diagnosis of diabetes, prediabetes and metabolic syndrome. Can J Diabetes, 2018. 42 S10-S5.

2. Zimmet PZ, Magliano DJ, Herman WH, Shaw JE: Diabetes: a 21st century challenge. Lancet Diabetes Endocrinol, 2014. 2 (1), 56-64.

3. Ashoori MR, Rahmati-Yamchi M, Ostadrahimi A, Pahlavan-Gharebaba R, Mobasseri M, Bakhtiyari S, et al.: Apelin-13 serum levels in type 2 diabetic obese women: possible relations with microRNAs-107 and 375. Turk Biyokim Derg, 2019. 44 (5), 667-75.

4. Gagliardino JJ, Elgart JF, Bourgeois M, Etchegoyen G, Fantuzzi G, Ré M, et al.: Diabetes primary prevention program: New insights from data analysis of recruitment period. Diabetes Metab Res Rev, 2018. 34 (1), e2943

5. Foretz $M$, Guigas B, Viollet B: Understanding the glucoregulatory mechanisms of metformin in type 2 diabetes mellitus. Nat Rev Endocrinol, 2019. 15 (10), 569-89.

6. Shi $M$, Loftus $H$, McAinch $A J, S u X Q$ : Blueberry as a source of bioactive compounds for the treatment of obesity, type 2 diabetes and chronic inflammation. J Funct Foods, 2017. 30 16-29.

7. Martirosyan D, Ashoori MR, Mirmiranpour H: The effect of low level-laser irradiation on antioxidant enzymes and mineral levels in serum of patients with type 2 diabetes mellitus. Bioact Compd Health Dis, 2020. 3 (5), 82-9.

8. Mathur R, Sahu K, Saraf S, Patheja P, Khan F, Gupta P: Low-level laser therapy as an adjunct to conventional therapy in the treatment of diabetic foot ulcers. Lasers Med Sci, 2017. 32 (2), 275-82.

9. Volpe CMO, Villar-Delfino PH, dos Anjos PMF, NogueiraMachado JA: Cellular death, reactive oxygen species (ROS) and diabetic complications. Cell Death Dis, 2018. 9 (2), 1-9.

10. Li R, Zhang Y, Rasool S, Geetha T, Babu JR: Effects and underlying mechanisms of bioactive compounds on type 2 diabetes mellitus and Alzheimer's disease. Oxid Med Cell Longev, 2019. 2019.

11. Tonin FS, Borba HH, Wiens A, Fernandez-Llimos F, Pontarolo R. Vitamins, antioxidants, and type 2 diabetes. Diabetes: Elsevier; 2020. p. 373-83.

12. Park S, Park S-Y: Can antioxidants be effective therapeutics for type 2 diabetes? Yeungnam Univ J Med, 2020.

13. Parmar JA, Modi GD: Trace elements (Copper and Zinc) in type 2 DM patients. Int J Clin Biochem Res, 2020. 7 (1).

14. Ashrafizadeh $\mathrm{H}$, Abtahi SR, Oroojan AA: Trace element nanoparticles improved diabetes mellitus; a brief report. Diabetes Metab Syndr, 2020.
15. Dubey P, Thakur V, Chattopadhyay M: Role of Minerals and Trace Elements in Diabetes and Insulin Resistance. Nutrients, 2020. 12 (6), 1864.

16. Demirturk-Gocgun O, Baser U, Aykol-Sahin G, Dinccag $\mathrm{N}$, Issever $\mathrm{H}$, Yalcin F: Role of low-level laser therapy as an adjunct to initial periodontal treatment in type 2 diabetic patients: a split-mouth, randomized, controlled clinical trial. Photomed Laser Surg, 2017. 35 (2), 111-5.

17. Stratmann B, Costea T-C, Nolte C, Hiller J, Schmidt J, Reindel J, et al.: Effect of cold atmospheric plasma therapy vs standard therapy placebo on wound healing in patients with diabetic foot ulcers: a randomized clinical trial. JAMA Netw Open, 2020. 3 (7), e2010411-e.

18. Dey A, Rasane P, Choudhury A, Singh J, Maisnam D, Rasane P: Cold plasma processing: A review. J Chem Pharm Sci, 2016. 9 2980-4.

19. Kolb JF, Mohamed A-AH, Price RO, Swanson RJ, Bowman $A$, Chiavarini $R$, et al.: Cold atmospheric pressure air plasma jet for medical applications. Appl Phys Lett, 2008. 92 (24), 241501.

20. Lademann O, Richter $\mathrm{H}$, Patzelt A, Alborova A, Humme D, Weltmann KD, et al.: Application of a plasma-jet for skin antisepsis: analysis of the thermal action of the plasma by laser scanning microscopy. Laser Phys Lett, 2010. 7 (6), 458-62.

21. Cheng K-Y, Lin Z-H, Cheng Y-P, Chiu H-Y, Yeh N-L, Wu T$K$, et al.: Wound healing in streptozotocin-induced diabetic rats using atmospheric-pressure argon plasma jet. Sci Rep, 2018.8 (1), 1-15.

22. Han $\mathrm{Y}$, Cheng J-H, Sun D-W: Activities and conformation changes of food enzymes induced by cold plasma: $A$ review. Crit Rev Food Sci Nutr, 2019. 59 (5), 794-811.

23. Rezaeinezhad A, Eslami P, Mirmiranpour $H$, Ghomi $H$ : The effect of cold atmospheric plasma on diabetesinduced enzyme glycation, oxidative stress, and inflammation; in vitro and in vivo. Sci Rep, 2019. 9 (1), 1-11.

24. Kim J, Kim JH, Chang B, Choi EH, Park H-K: Hemorheological alterations of red blood cells induced by non-thermal dielectric barrier discharge plasma. Appl Phys Lett, 2016. 109 (19), 193701.

25. Graves DB: The emerging role of reactive oxygen and nitrogen species in redox biology and some implications for plasma applications to medicine and biology. Journal of Physics D: Applied Physics, 2012. 45 (26), 263001.

26. Brun P, Pathak S, Castagliuolo I, PaluG BP: Helium Generated Cold Plasma Finely Regulates Activation of Human Fibroblast-Like. PLoS One, 2014. 9 (8), e104397.

27. Kurahashi T, Fujii J: Roles of antioxidative enzymes in wound healing. J Dev Biol, 2015. 3 (2), 57-70.

28. Prasad AS: Zinc is an antioxidant and anti-inflammatory agent: its role in human health. Front Nutr, 2014. 114. 